\title{
Para a saúde da criança. A educação do trabalhador nas teses médicas e nos jornais operários (São Paulo, início do século XX)
}

\author{
Liane Maria Bertucci
}

Resumo: o artigo discute como em São Paulo, nas primeiras décadas dos novecentos, o saber médico-científico, expresso de maneira privilegiada em teses da Faculdade de Medicina e Cirurgia da cidade, embasou propostas educacionais de doutores e permeou discussões e ações de trabalhadores relacionadas à questão da saúde da criança operária (entendida como criança trabalhadora ou filha de operários ou trabalhadores), dentro e fora da fábrica, no período de maior influência de ideias anarquistas entre o operariado de São Paulo (da virada para o século XX até os anos 1920). Destaco as discussões sobre o trabalho infantil e sobre a mulher-mãe operária, responsável primeira pela saúde dessas crianças.

Palavras-chave: educação para a saúde; teses médicas; jornais operários.

Abstract: this article discusses how medical and scientific knowledge in the early decades of the twentieth century was expressed in the theses of the College of Medicine and Surgery of São Paulo and used to form proposals for education in terms of the health of working-class children (understood as a working child or the daughter of workmen and laborers). The article also looks at how this knowledge spread over the discussions held by labor militants concerning the health of child workers inside and outside factories at a time when ideas of anarchism were at their most influential among the workforce (from the turn of the century to the 1920s). I highlight the discussions regarding child labor and the working mother, who was first and foremost responsible for the health of those children.

Key words: health education; medical theses; labor press.

* Doutora em História pela Universidade Estadual de Campinas (Unicamp), Pós-doutora pela Faculdade de Medicina da Universidade de São Paulo (USP) e Professora de História da Educação no Departamento de Teoria e Fundamentos da Educação (UFPR). 


\section{Introdução}

A participação de diferentes profissionais no Comitê Nacional Brasileiro do Primeiro Congresso Americano da Criança, realizado em Buenos Aires (Argentina) em 1916, explicitou a importância e pluralidade das discussões realizadas no Brasil sobre a criança ou menor, ou seja, indivíduo que contava, em geral, entre o e 15 anos; faixa etária que muitas vezes era denominada infância. ${ }^{1}$ O Comitê Nacional, presidido pelo doutor Arthur Moncorvo Filho, era formado por médicos, advogados, professores, militares, entre outros profissionais. Nas apresentações realizadas pelo Comitê, que foram publicadas em 1917, as questões sobre saúde da criança operária (entendida como criança trabalhadora ou filha de trabalhadores ou operários) e da mãe trabalhadora foram temas da Seção de Legislação Industrial e pontuaram as Seções de Direito, de Higiene, de Educação e de Assistência à Mãe e à Criança. ${ }^{2}$

O longo processo de "individualização da criança" (como escreveu Gélis), que acompanhou as mudanças da sociedade ocidental nos tempos modernos, foi combinado com a atenção com a mulher, muitas vezes mãe-trabalhadora, responsável primeira pela criação da prole. Esse processo foi marcado pela presença crescente dos médicos, cujas práticas de cura, entre o final dos setecentos e o século XIX, foram transformadas pela clínica, pela bacteriologia e pela medicina experimental: o corpo feminino, responsável por gestar nova vida, foi cada vez mais analisado, cuidado e medicado pelos doutores. Para muitos, o conhecimento científico que parecia livrar o homem de temores seculares (como o da varíola) e identificava microscópicos causadores de doenças, também poderia oferecer os meios para uma vida sadia de mães e filhos, mesmo para os mais pobres. A preocupação com a gravidez e o parto (com a progressiva intervenção médica no domínio das parteiras) e com os primeiros anos da criança, resultaram em práticas cada vez mais especializadas dos doutores e foram realizados inquéritos médicogovernamentais e programas educacionais para mulheres com o objetivo maior de elaborar e difundir ações que proporcionassem um desenvolvimento infantil sadio. A puericultura ganhou muitos adeptos, inclusive no Brasil. ${ }^{3}$

$\mathrm{Na}$ cidade de São Paulo das primeiras décadas dos novecentos, com a crescente industrialização que atraiu milhares de imigrantes e pessoas de outras partes do país, o destino de muitas crianças foi semelhante ao de seus pais: o trabalho fabril. ${ }^{4} \mathrm{E}$ a atenção médica com a criança operária extrapolou o intervalo

1 Neste artigo utilizo trabalhador e operário como sinônimos. Como sinônimos também foram usados os termos criança, infância e menor (mesmo considerando que, nos textos pesquisados, menor foi mais utilizado para nomear indivíduos entre 12 e 15 anos). Sobre criança (ser biológico), infância (uma construção social) e menor (denominação de infantes e jovens, que muitas vezes nomeou aqueles em situação de abandono ou delinquência), veja o livro seminal de ARIÈS, Philippe. História social da criança e da família. $2^{\text {a }}$ edição. Rio de Janeiro: Zahar, 1981 e, entre outros, DEL PRIORE, Mary (org.). História da criança no Brasil. $2^{a}$ edição. São Paulo: Contexto, 2000; HEYWOOD, Colin. Uma história da infância. Porto Alegre: Artmed, 2004; VENÂNCIO, Renato Pinto (org.). Uma história social do abandono de crianças. São Paulo: Alameda, 2010.

2 PRIMEIRO CONGRESSO AMERICANO DA CREANÇA. Comitê Nacional Brazileiro. Buenos Aires (Argentina), julho-agosto 1916. Rio de Janeiro: Imprensa Nacional, 1917. 2 volumes. O médico Arthur Moncorvo Filho era fundador e diretor do Instituto de Proteção e Assistência à Infância do Rio de Janeiro, que contou com filiais em diversas cidades brasileiras.

3 FAURE, Olivier. "O olhar do médico". In: CORBIN, Alain; COURTINE, Jean-Jacques; VIGARELLO, Georges (dir.). História do corpo. Volume 2, $2^{\mathrm{a}}$ edição. Petrópolis: Vozes, 2008, p. 13-55. FREIRE, Maria Martha de L. Mulheres, mães e médicos. Rio de Janeiro: Ed. FGV, 2009; GÉLIS, Jacques. "A individualização da criança". In: ARIÈS, Philippe; DUBY, Georges (dir.). História da vida privada. Volume 3. São Paulo: Companhia das Letras, 1991, p. 311-329. LATOUR, Bruno. La science em action. Paris: Éd. La Découverte, 1989.

4 São Paulo, segundo Carlos Santos, contava com 69.934 moradores em 1890 e somava 581.435 habitantes em 1920. Neste ano 100.821 imigrantes trabalhavam nas indústrias, no comércio e nos bancos da cidade; 
entre a vida intrauterina e os 5 anos, período considerado o efetivo objeto da puericultura por vários médicos, entre eles o doutor Clemente Ferreira, diretor do Dispensário de Lactentes do Serviço Sanitário do Estado de São Paulo nos anos 1910 (além de especialista em tuberculose). ${ }^{5}$ Preocupados com a formação da população brasileira, em meio ao movimento sanitarista, ${ }^{6}$ ações da Fundação Rockefeller ${ }^{7}$ e a difusão de ideias eugênicas, ${ }^{8}$ os médicos estavam atentos à saúde da criança operária e realizavam propostas, várias delas imbricadas com indicações educativas, que abrangiam da gestação e aleitamento materno à jornada de trabalho dos menores nas fábricas, como exemplificavam teses defendidas no início dos anos 1920 na Faculdade de Medicina e Cirurgia de São Paulo.

Educar para a manutenção da saúde dos filhos de trabalhadores também foi preocupação evidente de militantes operários na São Paulo dos primeiros anos do século XX. O Comitê Popular de Agitação Contra a Exploração dos Menores Operários, criado em março de 1917 e pouco a pouco controlado pelos anarquistas, foi um dos melhores exemplos dessa preocupação. Os comícios e conferências do Comitê Popular, que contribuíram para a realização da greve geral que paralisou São Paulo em julho daquele ano, enfatizavam a urgência da educação dos trabalhadores para manutenção da saúde dos seus filhos. A campanha que, segundo Lopreato "foi dirigida aos pais", alertava sobre abusos e maus tratos no ambiente fabril e para as "[...] consequências funestas da falta de ar, de espaço, de higiene e de luz sobre a saúde dos pequenos trabalhadores". 9

Este artigo discute como em São Paulo, nas primeiras décadas do século XX, o saber médico-científico, expresso de maneira privilegiada nas teses da Faculdade de Medicina e Cirurgia, foi utilizado para a elaboração de propostas relacionadas à saúde da criança trabalhadora e também permeou debates e ações de militantes operários que tinham como objetivo a constituição sadia desta criança.

\section{Um tema em destaque: o trabalho da criança na fábrica}

Na segunda metade dos anos 1910, entraves comerciais e a carestia (notadamente dos gêneros alimentícios), impulsionados pela Primeira Guerra Mundial, atingiram proporções alarmantes em São Paulo e a queda vertiginosa do poder de compra do salário do trabalhador foi conjugada com o aumento do número de menores contratados por donos de fábricas sob a alegação de dificuldades financeiras: o salário de uma criança representava, em casos extremos, apenas $10 \%$ do dinheiro que era pago a um operário adulto. ${ }^{10}$

entre eles os italianos eram a maioria, seguidos pelos portugueses e espanhóis. Muitos dos trabalhadores contabilizados como nacionais eram filhos de imigrantes. SANTOS, Carlos J. Ferreira dos. Nem tudo era italiano. São Paulo: Annablume, 1998, p. 32; 49-50.

5 FERREIRA, Clemente. "A puericultura em São Paulo". PRIMEIRO CONGRESSO AMERICANO DA CREANÇA, 1917, v.2, p. 84.

6 Extensa é a bibliografia sobre o movimento sanitarista, que tinha como objetivo a elaboração e realização de políticas de saúde pública para o país (o que incluía a educação para a saúde). Veja, entre outros: HOCHMAN, Gilberto. A era do saneamento. São Paulo: Hucitec, 1998.

7 Entre os estudos sobre a atuação da Fundação Rockefeller em São Paulo, veja: FARIA, Lina. Saúde e política. Rio de Janeiro: Ed. Fiocruz, 2007. Sobre a parceria Fundação Rockefeller e Faculdade de Medicina e Cirurgia de São Paulo: MARINHO, Maria Gabriela S.M.C. Elites em negociação. Bragança: Ed. USF, 2003.

8 Sobre a eugenia, fundada em estudos sobre hereditariedade e estatística, que pretendia a multiplicação de homens considerados bem formados e evitar a procriação dos degenerados, veja como exemplo da diversificada bibliografia nacional, além do livro de MARQUES, Vera Regina Beltrão. Medicalização da raça. Campinas: Ed. Unicamp, 1994, os textos do livro MOTA, André; MARINHO, Maria Gabriela S.M.C. (org.). Eugenia e história. São Paulo: FFMUSP; UFABC; Casa Soluções Editora, 2013.

9 LOPREATO, Christina Roquette. O espírito da revolta. São Paulo: Annablume, 2000, p. 87 e p. 89-90.

10 LOPREATO. O espírito da revolta, p. 79. Confira também: MOURA, Esmeralda B. B. de. Mulheres e menores 
Realizando tarefas que extrapolavam sua capacidade física, trabalhando durante jornadas de 10 a 12 horas, em locais insalubres e em meio a mecanismos perigosos, crianças que, por vezes, tinham menos de 10 anos de idade, eram contadas entre as pessoas empregadas nas fábricas e oficinas de São Paulo (situação que perduraria nos anos seguintes). ${ }^{11}$ Criado em 1911, o Departamento Estadual do Trabalho publicou no primeiro número de seu boletim um levantamento parcial sobre a indústria têxtil paulista e, entre os 10.204 operários arrolados (cerca de $80 \%$ do total de trabalhadores do setor), 371 tinham menos de 12 anos e 2.581 contavam entre 12 e 16 anos. Na segunda metade dos anos 1910, o agravamento dessa situação, somado aos repetidos relatos de acidentes de trabalho envolvendo menores, resultou na publicação de denúncias em jornais de grande circulação em São Paulo (entre eles, O Estado de S. Paulo, A Capital e Fanfulla) e, principalmente, na mobilização da imprensa operária, de organizações de trabalhadores e na criação em 1917 do Comitê Popular de Agitação Contra a Exploração dos Menores Operários. ${ }^{12}$ A organização deste comitê traduziu para a população de São Paulo a magnitude do problema do trabalho dos menores e representou um alerta excepcional entre os próprios trabalhadores para um tema que há anos era motivo de discussões e proposições de militantes operários.

No final do século XIX, quando ideias socialistas agitaram a capital paulista e a organização e os rumos de um partido dividiram opiniões dos indivíduos que comungavam este ideário, o jornal O Socialista publicou, em 1897, como determinação programática: "proibição do trabalho às crianças menores de 15 anos, sem distinção de sexo". ${ }^{33}$ Alguns anos depois, em meio à crescente influência do anarquismo entre os trabalhadores, a questão do combate ao trabalho da criança foi combinada com a tese da formação (física e intelectual) do menor como requisito para a transformação social.

Jornais anarquistas, que seriam os grandes arautos dessas ideias, começaram a circular em São Paulo no final dos oitocentos; os primeiros em italiano e, a partir de 1902 com a publicação do O Amigo do Povo, vários deles foram editados regularmente em português. A tese anarquista, forjada na Europa em meados do século XIX, da organização mínima, que condenava a ordem estatal e partidária, ganhou adesão ou pelo menos a simpatia de muitos trabalhadores irmanados pelas condições de vida e trabalho encontradas na cidade de São Paulo e outras localidades brasileiras. Desde os primeiros anos do século XX até meados dos anos 1920 foi significativa a difusão entre o operariado paulista do sindicato de ofício (desligado de obras de beneficência e do cooperativismo), lugar para a conscientização dos trabalhadores e para a organização da luta pela derrocada da sociedade existente. Notícias de sindicatos, muitos deles efêmeros e de existências irregulares, ocuparam várias colunas das páginas dos periódicos que se autodenominavam anarquistas ou libertários.

Longe de ser homogêneo, o movimento anarquista em São Paulo aglutinou diversas tendências. O jornal A Terra Livre, que começou a circular em 1905, no primeiro número informava seus leitores: "somos socialistas e anarquistas", contra a propriedade privada e o Estado. ${ }^{14}$ Influenciados por pensadores como Eliseu Reclus,

no trabalho industrial. Petrópolis: Vozes, 1982.

11 Entre outros: O conto do vigário das leis. Operária de oito anos vítima de um desastre! A Vanguarda. São Paulo, n²7, 29 mar. 1921, p.1.

12 LOPREATO. O espírito da revolta, p. 77-95. Boletim do Departamento Estadual do Trabalho. Ano I, nº 1 e 2. São Paulo, 1912, p. 38.

13 O Socialista. São Paulo, ano II, $\mathrm{n}^{\circ} 48,1^{\circ}$ maio 1897 , p.4.

14 A Terra Livre. São Paulo, ano I, nº 1, 6 dez. 1905, p.1. 
Enrico Malatesta, Francisco Ferrer y Guardia, Pierre-Joseph Proudhon e Piotr Kropotkin, os militantes libertários mantinham contato com países da Europa, recebendo e enviando publicações, efetivando em terras brasileiras um amalgamar de ideias.

Um tema permeou a ação dos agregados sob o nome anarquista: a educação. Educação, embasada pela ciência (entendida como neutra porque fruto de experimentos racionais e análises repetidas), ${ }^{15}$ para conscientização da necessidade e possibilidade de mudança social; educação para formar revolucionários que construiriam um mundo novo. Em São Paulo os anarquistas desenvolveram ações educacionais através da organização de escolas modernas, cujo grande inspirador foi Ferrer; realizaram e patrocinaram conferências e apresentações artísticoculturais, em meetings e nos sindicatos, e editaram periódicos, principalmente jornais, que buscaram formar o trabalhador consciente através de artigos, notícias e denúncias das mazelas da sociedade. ${ }^{16}$ Nas páginas dos jornais operários a atenção com a criança foi destacada, pois de sua boa formação dependia o futuro. Nesses jornais, o trabalho do menor nas fábricas (chamadas "presídios industriais" no A Lucta Proletária de 1908) traduzia a mais cruel exploração capitalista. Eram repetitivos os textos descrevendo crianças operárias cadavéricas saindo de fábricas, "sem ar, sem luz e sem nenhuma prescrição higiênica" (como no A Voz da União de 1923), ou relatos sobre maus tratos e acidentes, por vezes fatais, com menores. ${ }^{17}$ Mais que informar, essas denúncias recorrentes difundiam ideias que educavam, de maneira não formal, os leitores dos jornais (e os ouvintes destes leitores $)^{18}$ sobre a gravidade do emprego de crianças em estabelecimentos fabris.

Mas, várias crianças operárias, por vezes como aprendizes, dividiram o espaço de trabalho com seus pais, pois não foram poucos aqueles que utilizaram a mão de obra de seus filhos para garantir, totalmente ou em parte, o sustento do lar. Miséria e ignorância, afirmava artigo do Jornal Operário, faziam o homem "[...] lançar mão do trabalho de seus filhos; pegam numa criança de 10 ou 12 anos e levam-na a uma oficina [ou fábrica]". ${ }^{19}$

Discutida nos Congressos Operários Brasileiros de 1906, 1913 e 1920, a questão do trabalho do menor foi pautada no Segundo Congresso Operário Estadual de São Paulo, em 1908. O Tema $n^{\circ} 11$ da terceira sessão desse Congresso era: "Será conveniente propagar nas organizações operárias a não admissão dos menores de 14 anos no trabalho?”. O autor da proposta temática ressaltava a necessidade de ações dos operários "[...] para conseguir a abolição dessa odiosa exploração à qual estão subjugadas as nossas crianças em prejuízo da sua saúde e da sua

15 CODELLO, Francesco. A boa educação. Volume 1- A teoria. São Paulo: Imaginário, 2007; SEIXAS, Jacy Alves de. "Anarquismo e socialismo no Brasil: as fontes positivistas e darwinistas sociais". História \& Perspectivas, Uberlândia, nº 12/13 p. 133-148, jan.-dez., 1995.

16 BERTUCCI, Liane Maria. Saúde: arma revolucionária. Campinas: Publicações CMU/Unicamp, 1997. JOMINI, Regina C. Mazoni. Uma educação para a solidariedade. Campinas: Pontes; Ed. Unicamp, 1990.

17 A Lucta Proletária. São Paulo, ano III (segunda fase), no 6, 22 fev. 1908, p. 3. A Voz da União. São Paulo, ano I, no 12,7 mar. 1923, p.2.

18 Em 1911, entre os 10.204 operários da industrial têxtil paulista recenseados em 23 estabelecimentos, 5.189 sabiam ler e escrever, 3.801 eram analfabetos e 1.214 de "grau de instrução ignorado". Boletim do Departamento Estadual do Trabalho, 1911, p. 39. Entre os historiadores que em seus estudos abordaram leitores como potenciais difusores de ideias, muitas vezes reinterpretadas, estão: THOMPSON, Edward P. A formação da classe operária inglesa. Rio de Janeiro: Paz e Terra, 1987, especialmente o volume 2 “A maldição de Adão"; DAVIS, Natalie Zemon. "O povo e a palavra impressa”. In: DAVIS, Natalie Zemon. Culturas do povo. $2^{\text {a }}$ edição. Rio de Janeiro: Paz e Terra, 2001, p. 157-185, e CHARTIER, Roger. Práticas e representações: leituras camponesas em França no século XVIII. In: CHARTIER, Roger. A história cultural. Lisboa: Difel, 1990, p. 141-163.

19 Jornal Operário. São Paulo, ano I, no 9, 12 nov. 1905, p.3. Confira, sobre local de trabalho comum de pais e filhos: Folha do Povo. São Paulo, ano II, no 62, 24/25 maio 1909, p.3, entre muitos outros. 
inteligência". ${ }^{20}$ Com atenção renovada sobre a questão do menor, no início dos anos 1920 o jornal A Plebe denunciou:

De há muito que os militantes proletários protestam contra a exploração infamérrima a que estão sujeitos nos ergástulos industriais os filhos do povo. [...] Agora, porém, com o horrível caso do menor estraçalhado pelos cães da fábrica Penteado, a diretoria do Serviço Sanitário lembrou-se de que há leis proibitivas do emprego de crianças na indústria e multou em 1.000\$ a Companhia Paulista de Aniagens. Que irrisão! Esse mísero conto de réis, multiplicado por muitas centenas será reconquistado pela empresa no roubo ao esforço dos menores. ${ }^{21}$

Motivo de reiteradas denúncias de militantes operários, que entendiam a educação dos pais como meio eficiente para evitar o trabalho prematuro dos filhos, a questão do trabalho de crianças em estabelecimentos fabris também foi objeto de teses defendidas na Faculdade de Medicina e Cirurgia de São Paulo, em um período de multiplicação dos debates sobre a necessidade da difusão de práticas individuais e coletivas de saúde para a boa formação da "raça brasileira". Muitos desses médicos acreditavam que filhos de trabalhadores bem constituídos física e mentalmente resultariam no operário brasileiro saudável de amanhã, cumpridor de seus deveres e colaborador para o progresso do país. Como afirmava José Guilherme Whitaker, em tese de doutoramento defendida em 1923 naquela faculdade, o problema "urgente [e] imperativo" da segurança e saúde do operário adquiria dimensão extraordinária quando se tratava do menor, porque o menor era "o futuro". ${ }^{22}$

Elaborada a partir de levantamento estatístico realizado em São Paulo e região, o estudo de Whitaker, além de fazer apelo para que os patrões cumprissem a legislação sanitária estadual de 1918, denunciava a carência de dados governamentais sobre o operariado e o esforço "quase inútil" de tentar identificar as idades dos menores empregados nas fábricas, pois eram frequentemente calculadas e registradas pelo industrial a partir da "importância [salarial] que lhes paga". ${ }^{23}$ O Código Sanitário do Estado de São Paulo de 1918, citado por Whitaker, estabelecia:

Artigo 210 - Nas fábricas, oficinas e quaisquer outros estabelecimentos industriais, bem como nas construções, é proibido o trabalho de pessoas menores de doze anos.

Artigo 211 - Entre doze e quinze anos, pode o menor, mediante consentimento de seus representantes legais, ser admitido a trabalhar por tempo que não exceda de cinco horas por dia, em serviços moderados, que não lhe prejudiquem a saúde ou embaracem a instrução escolar. ${ }^{24}$

Quantos pais, para a satisfação de muitos industriais (e com a conivência destes), premidos por necessidades financeiras ou ignorantes dos malefícios do trabalho prematuro, teriam omitido a real idade de seus filhos para que crianças

20 A Lucta Proletária. São Paulo, ano III (segunda época), n 14, 10 maio 1908, p.5. O autor lembrava também que as crianças em casa significavam mais empregos para operários adultos.

21 A exploração dos menores. A Plebe. São Paulo, ano V, n 196, 18 nov. 1922, p. 4.

22 WHITAKER, José Guilherme. "A questão do trabalho de menores em fábricas em São Paulo". (Tese de doutoramento, Faculdade de Medicina e Cirurgia de São Paulo). São Paulo: Secção de Obras d' O Estado de S. Paulo, 1923, p. 1-2.

23 WHITAKER. "A questão do trabalho de menores em fábricas em São Paulo", p. 3.

24 DECRETO n 2.918, 9 de abril de 1918. Dá Execução ao Código Sanitário do Estado de São Paulo. São Paulo. Coleção das Leis e Decretos do Estado de São Paulo. Tomo XXVII. São Paulo: [s.n.], 1919, p. 75. 
fossem empregadas? Pergunta que vários militantes operários poderiam ter feito, mas Whitaker não fez, ele apelou para a lei. Anos antes, discutindo a questão da responsabilidade paterna, o advogado Taciano Antonio Basílio também apelou para a lei, mas fez sugestão extrema. Em 1916, no Primeiro Congresso Americano da Criança, Basílio sugeriu a retirada do pátrio poder de pais que insistissem em encaminhar seus filhos com menos de 12 anos para o trabalho fabril porque, segundo ele, o pátrio poder era "um dever e obrigação à proteção aos filhos" e não "compensação reivindicatória" ou um direito absoluto. Caberia ao pai "dirigir a educação do filho, exigir-lhe obediência, guardá-lo em sua companhia, castigarIhe, mas não o de sacrificar-Ihe a saúde, futuro e dignidade". ${ }^{25}$

Para Basílio, assim como para Whitaker, era preciso coibir abusos. Em sua tese $A$ questão do trabalho de menores em fábricas em São Paulo, este médico escreveu que mesmo considerando os encargos da fabricação, as vicissitudes da concorrência e a atividade incessante das máquinas modernas, não era possível aceitar que crianças trabalhassem "[...] além do tempo que Ihes permitem as forças, de dia e de noite, em oficinas cuja atmosfera pode alterar a sua organização delicada". ${ }^{26}$ Utilizando como exemplo as péssimas condições higiênicas de diversas fábricas de tecidos, afirmava:

Chega a ser um crime permitir que crianças, em plena época de desenvolvimento físico, e, por isso mesmo, com reduzida capacidade orgânica de resistência, vivam num ambiente viciado [como o de várias tecelagens] e talvez contaminado pela presença, sempre possível, de operários doentes, aos quais não se proíbe nem mesmo o hábito asqueroso de cuspir no chão. ${ }^{27}$

Whitaker propunha a organização no Serviço Sanitário paulista de uma seção destinada exclusivamente à Higiene Industrial, formada por médicos-inspetores que avaliariam de maneira privilegiada a saúde do menor trabalhador, cujo organismo estava em plena fase de desenvolvimento.

O olhar exercitado de um médico raramente enganar-se-á a esse respeito [o portador de enfermidade]. A aparência da criança, a natureza do seu trabalho, as condições sanitárias da fábrica em que está empregada, seriam indicações para se proceder ou não a exame médico. Com esta vigilância afastar-se-á de trabalhos inconvenientes grande número de crianças que de outro modo seriam consideradas capazes, e correriam a uma ruína fatal. ${ }^{28}$

Mas, para José Guilherme Whitaker eram as leis escolares aquelas que protegeriam melhor a criança: frequentar a escola era fundamental, porque "em vez de proibir será melhor prevenir”. Se nas conferências e comícios operários de 1917 o tema educação dos pais foi primordial quando a questão era afastar a criança do universo fabril, na tese de doutoramento de 1923 era a educação escolar dos filhos de trabalhadores que ganhava ênfase. Na tese, a educação profissional em instituições especializadas foi abordada de maneira destacada porque, segundo Whitaker, estas escolas deveriam instruir racionalmente sobre um ofício, incluindo "preceitos de higiene segundo o gênero de trabalho", alargando horizontes e

25 BASÍLIO, Taciano Antonio. "Trabalho de menores e o pátrio poder". PRIMEIRO CONGRESSO AMERICANO DA CREANÇA, 1917, v.1, p.221-222.

26 WHITAKER. "A questão do trabalho de menores em fábricas em São Paulo", p.7.

27 WHITAKER. "A questão do trabalho de menores em fábricas em São Paulo", p. 12

28 WHITAKER. “A questão do trabalho de menores em fábricas em São Paulo”, p. 32. 
aguçando a inteligência dos futuros trabalhadores. Era preciso suscitar no menor "a ambição de ser um operário modelo, instruído, seguindo de perto e até forçando a marcha do progresso". 29

Desta forma, a partir de diversas perspectivas, eram cada vez mais questionadas afirmações como a de Antônio Francisco Bandeira Júnior, que em 1901 escreveu que a fábrica era lugar de formação do "elemento fabril do futuro". ${ }^{30}$ Entendido por muitos como um grave problema, o trabalho das crianças nas fábricas, segundo o advogado Taciano Antonio Basílio, poderia até justificar a "[...] discreta intervenção do Estado no tocante ao regime do trabalho dos menores, em que a inobservância da higiene e o excessivo e prematuro labor determinam terríveis males que suprimem ou inutilizam o indivíduo". ${ }^{31}$ Palavras que, sem grandes alterações, poderiam ser escritas pelo doutor Whitaker. Quanto aos militantes operários, provavelmente, endossariam a parte final das considerações, isto é, a referente aos malefícios para a criança do trabalho antihigiênico, excessivo e prematuro.

\section{Para o progresso do país ou para a revolução?}

Afastar as crianças das fábricas, esse ideal que perpassou discursos de militantes operários e de médicos (além de outros profissionais atentos ao universo fabril) foi repetidamente conjugado com aquele que afirmava ser a maternidade e os cuidados com os filhos e a casa o destino natural da mulher, reiterando "[a] divisão sexual do trabalho e do espaço social que a racionalidade do século XIX levou aos seus mais extremos limites", como escreveu Perrot. ${ }^{32}$ Entretanto a mulher, "rainha do lar", senhora do mundo privado, muitas vezes realizou funções que extrapolavam o limite doméstico, trabalhando para o sustento da família ou o seu próprio. No Brasil, desde os tempos coloniais, atividades como as de costureira, bordadeira, lavadeira e quitandeira, que combinavam a casa e a rua, foram fundamentais para a economia familiar. Nas primeiras décadas do século XX, entre estas atividades, as que prescindiam da circulação constante pelos espaços públicos eram as consideradas mais apropriadas para uma senhora ou senhorita "de família", como as de costureira ou bordadeira, cujo trabalho era efetuado em casa (de preferência) ou em ateliês nos quais apenas mulheres trabalhavam. Eram cada vez mais desqualificadas atividades como as da lavadeira, que ia e vinha para buscar e levar roupas, ou da vendedora ambulante de quitandas, que circulava pelas ruas e praças da cidade. Paralelamente, a mulher/mãe/professora primária ganhou valor superlativo a partir da virada para o século XX.33

Em São Paulo, o crescimento fabril dos novecentos proporcionou uma nova e ampliada perspectiva à visão do trabalho feminino fora de casa, pois era

29 WHITAKER. "A questão do trabalho de menores em fábricas em São Paulo”, p. 22, 39-40.

30 BANDEIRA JUNIOR, Antônio Francisco. “A indústria no Estado de São Paulo em 1901”. In: PINHEIRO, Paulo Sérgio; HALL, Michel M.(org.) A classe operária no Brasil. Volume 2 - Documentos. São Paulo: Brasiliense, 1981, p. 29.

31 BASÍLIO. "Trabalho de menores e o pátrio poder", p. 217-219.

32 PERROT, Michelle. "O elogio da dona-de-casa no discurso dos operários franceses do século XIX". In: PERROT, Michelle. As mulheres ou os silêncios da história. Bauru: Edusc, 2005, p. 171.

33 Entre outros: DIAS, Maria Odila L. da Silva. Quotidiano e poder em São Paulo do século XIX. São Paulo: Brasiliense, 1984; LOURO, Guacira Lopes. "Mulheres na sala de aula”. In: DEL PRIORE. Mary (org.) História das mulheres no Brasil. $5^{\text {a }}$ edição. São Paulo: Contexto, 2001, p. 443-481; MARTINS, Valter. Mercados urbanos, transformações na cidade. Campinas: Ed. Unicamp, 2010, p. 92-97, 241-254; SOIHET, Rachel. "Mulheres pobres e violência no Brasil urbano". In: DEL PRIORE, Mary (org.). História das mulheres no Brasil. $5^{a}$ edição. São Paulo: Contexto, 2001, p. 362-400; TRINDADE, Etelvina Maria de C. Clotildes ou Marias, mulheres de Curitiba na Primeira República. Curitiba: Farol do Saber, 1996, p. 261-280. 
evidente o número expressivo de mulheres no espaço da fábrica, principalmente na indústria têxtil, que parecia combinar a modernidade da máquina com antigas atividades consideradas próprias das mulheres. Essas fábricas e oficinas de juta, tecidos de algodão e de seda, camisas e meias, fitas e passamanarias, cobertores e outros produtos, somavam 31 estabelecimentos na cidade em 1911 e, segundo o Boletim do Departamento Estadual do Trabalho, em 23 desses estabelecimentos que foram recenseados trabalhavam 6.801 mulheres, mais que o dobro dos 2.648 homens. Entre as operárias, 1.706 eram maiores de 22 anos, 2.966 tinham de 16 a 22 anos, 1.885 tinham de 12 a 16 anos e 244 tinham idade inferior a 12 anos. Neste boletim, a sétima tecelagem visitada foi descrita como "verdadeiro luxo":

[...] ar e luz em abundância, ventilação, seções separadas, tinturaria ao ar livre, correias e engrenagens protegidas, jardim circundando a fábrica, aparelhos extintores de incêndio por toda parte, W.C. e vestiários separados para os operários de ambos os sexos. ${ }^{34}$

Essas palavras, que descreviam o que era considerado uma exceção, podem fornecer a medida da precariedade das instalações, da falta de higiene, da insalubridade e, muitas vezes, da promiscuidade das tecelagens de São Paulo, locais de maciça presença feminina - uma preocupação permanente de médicos e militantes operários, principalmente devido às crianças que seriam geradas por essas mulheres. ${ }^{35}$

Em 1909, artigo do jornal Folha do Povo afirmava:

Há profissões tão nocivas à saúde que põem em perigo a vida da criança mesmo no seio materno. Refiro-me às indústrias em que se empregam o mercúrio, o chumbo e o fósforo; refiro-me ao ofício de costureira e a tantos outros, todos cheios de perigo para a mulher grávida e de seu filho em gestação. ${ }^{36}$

Anos depois, em 1923, em sua tese Da protecção à operária grávida, o doutor Álvaro Roca Dordal escreveu sobre os perigos que representavam para o feto substâncias como chumbo, fósforo, mercúrio, arsênico e fumo e apontou como proibitivos para as gestantes os trabalhos que exigissem movimentação constante e permanência de pé. O tema trabalho da mulher grávida gerou debates legislativos no Brasil desde os tempos do Império. Em 1822 José Bonifácio de Andrada e Silva enviou representação à Assembleia Nacional Constituinte que previa o afastamento de trabalhos violentos e ininterruptos de escravas a partir do terceiro mês de gravidez; no século XX leis de alguns estados e também do governo federal concediam licença maternidade para as professoras; entretanto, as determinações relativas às mulheres que trabalhavam nas oficinas e fábricas eram genéricas, muitas vezes combinadas com a atenção ao menor e atreladas às determinações sobre salubridade e duração da jornada de trabalho. ${ }^{37}$ Segundo

34 BOLETIM DO DEPARTAMENTO ESTADUAL DO TRABALHO, 1912, p. 35-36, 38, 41-68, 75. Segundo informava o próprio Boletim, os dados de 755 trabalhadores dessas 23 fábricas, inclusive o sexo, não foram informados/computados (p. 75).

35 Veja: BERTUCCI. Saúde: arma revolucionária, p. 169-212. Questões morais eram repetidamente discutidas nos artigos de jornais operários que condenavam o espaço fabril.

36 A incerteza da vida. Folha do Povo, São Paulo, ano II, n 88, 4 jul.1909, p. 2. O médico Lessa escreveu que produtos tóxicos, como mercúrio ou arsênico, eram "[...] facilmente absorvidos e eliminados todos em grande parte pelo leite [materno]”. LESSA, Severino. “A mãe operária e o aleitamento”. PRIMEIRO CONGRESSO AMERICANO DA CREANÇA, 1917, v. 2, p.145-146.

37 DORDAL, Álvaro Roca. "Da protecção à operária grávida". (Tese de doutoramento, Faculdade de Medicina e Cirurgia de São Paulo). São Paulo: P.M. Higgins \& C.R.B. de Iguape, 1923, p.10-11, 20-21. SILVA, 
Dordal, foi o governo estadual paulista que primeiro concorreu para a proteção da mãe trabalhadora e seu filho recém-nascido com o Código Sanitário do Estado de 1918, pois, paralelamente à regulamentação do trabalho dos menores nas fábricas, este código determinou no Artigo 214 a proibição "[do] trabalho de mulheres durante o último mês de gravidez e o primeiro de puerpério, em quaisquer estabelecimentos industriais". ${ }^{38}$

Para o médico, mesmo com as burlas de patrões (desejosos de manter a produção) e de operárias (que precisavam dos dois meses de salário e temiam não recuperar o emprego depois do afastamento), a lei era o instrumento que, principalmente se fosse complementada, protegeria a operária grávida, colaborando para que esta cumprisse a "[...] função natural e social da mulher [que] é gerar o filho que nutre e educa, entregando-o à família, à nação e à espécie”. Para Dordal, a partir da constatação que "[...] a necessidade de luta pela vida determina a entrada da mulher para o mundo do trabalho [e] por ser esta quase desamparada materialmente e ignorante dos princípios de higiene gravídica", 39 era imperioso instruir a mulher operária sobre preceitos que colaborariam para uma gravidez saudável e educá-la para que seguisse as orientações médicas sobre como criar seu filho desde o nascimento. E a mulher deveria manter os cuidados necessários com a saúde da prole mesmo quando voltasse a trabalhar na fábrica. Uma das preocupações de Dordal era a questão da amamentação dos filhos pela mãe operária, um tema recorrente entre os médicos.

Em 1926, o estudo de doutoramento Da protecção à primeira infância em São Paulo, de Vicente Pascarelli, advertia sobre os perigos dos "conselhos de vizinhas" sobre amamentação (tais como, ingestão de cerveja para aumentar a quantidade de leite materno) e alertava sobre os riscos do "aleitamento artificial" (com leite de vaca) de crianças de 0 até 1 ano, notadamente devido à falta de higiene das mamadeiras, por vezes improvisadas em garrafas não esterilizadas, e ao desconhecimento da procedência do leite que seria ingerido pela criança. O médico repudiava também o antigo costume feminino de misturar leite e água (supostamente para diminuir o teor de gordura) para alimentar os filhos pequenos e condenava a alimentação precoce de crianças com mingaus ou papas. ${ }^{40}$ No mesmo ano, Cyro de Oliveira Arruda escreveu em sua tese Contribuição para o estudo da mortalidade infantil em São Paulo:

[...] mães dão aos seus filhinhos os alimentos mais disparatados, lembramo-nos ainda de uma criança que deu entrada na clínica pediátrica da faculdade apresentando intoxicação alimentar, a qual se recusava tomar leite sob qualquer forma. Sá aceitava caldo de feijão, arroz, ou qualquer alimento de adulto. ${ }^{41}$

José Bonifácio de Andrada e. "Representação à Assembleia Geral Constituinte e Legislativa do Império Brasileiro sobre a escravatura”. In: SILVA, Elisiane da; NAVES, Gervásio R.; MARTINS, Liana B. (org.) José Bonifácio. $2^{a}$ edição. Brasília: Fund. Ulysses Guimarães, 2013, p. 177.

38 DORDAL. "Da protecção à operária grávida", p. 35. Confira: DECRETO n 2.918, 9 de abril de 1918. Dá Execução ao Código Sanitário do Estado de São Paulo, 1919, p. 76.

39 DORDAL. "Da protecção à operária grávida", p. 13 e 16. Para o médico, a lei deveria ter três partes: a do repouso obrigatório para mulher; a que garantisse seu contrato de emprego, e a da indenização pelo período de exclusão temporária do trabalho. O doutor fez propostas para viabilizar tais ideias, também sugeriu a organização nas grandes fábricas de consultórios médicos para grávidas e insistiu para a manutenção governamental das maternidades das cidades (p. 33-37, 46-52).

40 PASCARELLI, Vicente. "Da protecção à primeira infância em São Paulo". (Tese de doutoramento, Faculdade de Medicina de São Paulo). São Paulo: Irmão Ferraz, 1926, p. 18-20, 31-36. É preciso pelo menos assinalar a força do cuidar tradicional compartilhado por mulheres (inclusive as consideradas educadas e ricas) e que o saber médico condenava. Sobre costume, que extrapola um grupo social, uma ambiência plena de tradições vividas cotidianamente veja: THOMPSON, Edward P. Costumes em comum. São Paulo: Companhia das Letras, 1998, p. 13-24.

41 ARRUDA, Cyro de Oliveira. “Contribuição para o estudo da mortalidade infantil em São Paulo”. (Tese de 
Para esses médicos o ideal era que quando voltasse a trabalhar a mulher operária deixasse seu filho sob os cuidados de uma pessoa adulta bem instruída (segundo os padrões médicos) e que a criança fosse levada mais de uma vez até a mãe para amamentação. ${ }^{42} \mathrm{~A}$ realidade, como constatavam os doutores, era outra: muitas crianças pequenas ficavam sob os cuidados diários de irmãos mais velhos e várias mães precocemente deixavam de amamentar seus filhos.

Utilizando dados estatísticos do Serviço Sanitário do Estado sobre a mortalidade de crianças de o a 1 ano, o doutor Arruda era categórico “[...] ensinemse à mulher paulista os preceitos da puericultura e em pouco tempo a mortalidade infantil em nossa terra será uma sombra que passou". Segundo esses dados, de cada 1.000 crianças nascidas em São Paulo no ano de 1924 apenas 832 atingiram 1 ano de idade e do total de 13.158 falecimentos na cidade no mesmo ano, 3.896, ou seja $29,60 \%$, eram de menores de 1 ano. As moléstias que mais matavam essas crianças eram as do aparelho digestivo, que representavam 48,59\% das mortes, e as motivadas por causas pré-natais, natais ou neonatais, que totalizavam $17,54 \%$ desses óbitos. ${ }^{43} \mathrm{~A}$ estatística reforçava argumento defendido, entre outros, pelo renomado doutor Martagão Gesteira (professor catedrático de Clínica Médica e Higiene Infantil da Faculdade de Medicina da Bahia), que apontava os "erros da dietética" entre as principais causas da morte de crianças pequenas. Para Gesteira, o maior desses erros era o abandono prematuro do aleitamento materno, muitas vezes devido à necessidade da mãe trabalhar longe dos filhos. ${ }^{44}$

Entretanto, para os médicos os problemas relacionados à amamentação não eram apenas esses. Em uma sociedade que valorizava a existência da mulher entre a puberdade e a menopausa, ${ }^{45}$ o papel cada vez mais preponderante da medicina no universo feminino se expressava inclusive na tentativa de regulação da amamentação de crianças no seio materno. Assim, as mulheres que amamentavam seus filhos deveriam seguir preceitos ditados pelos doutores, mesmo que isso contrariasse costumes seculares. Como escreveu Arruda:

Entre as crianças alimentadas ao seio, o processo de se lhes dar de mamar toda a vez que choram é também geralmente seguido, com graves prejuízos para a mãe e para o filho. Entre as nossas mães de família o hábito é tão arraigado que julgam impossível que uma criança regularmente alimentada possa passar 3 horas sem necessitar de alimento. ${ }^{46}$

Segundo os doutores a urgência da educação da mãe trabalhadora era evidente, pois apenas uma mulher educada tornaria efetivamente possível a reversão do quadro de doença e morte prematura de crianças que, muitas vezes, já nasciam debilitadas. Como afirmou Ulysses Gonçalves de Souza e Silva, em tese de 1921, "[...] mães bem orientadas ficam as melhores auxiliares dos governos e da ciência, no que diz respeito à puericultura prática". ${ }^{47}$ Três anos depois, no estudo

doutoramento, Faculdade de Medicina de São Paulo). São Paulo: Typ. S. José, 1926, p. 22.

42 O doutor Jayme Americano considerou a possibilidade de a mãe operária amamentar o filho em casa, concluindo que tal prática era inviável devido ao tempo gasto (deveriam ser três idas e vindas) e a fadiga. AMERICANO, Jayme Cardoso. "Da protecção ao lactante em nosso meio operário". (Tese de doutoramento, Faculdade de Medicina e Cirurgia de São Paulo). São Paulo: Typ. Martins, 1924, p. 10-13.

43 ARRUDA. "Contribuição para o estudo da mortalidade infantil em São Paulo", p. 15-19, 24-25.

44 GESTEIRA, Martagão. Causas da morbidade e mortalidade infantil. PRIMEIRO CONGRESSO AMERICANO DA CREANÇA, 1917, v.2, p. 162-163.

45 PERROT. "O elogio da dona-de-casa no discurso dos operários franceses do século XIX”, p. 177.

46 ARRUDA. "Contribuição para o estudo da mortalidade infantil em São Paulo", p. 23.

47 SILVA, Ulysses Gonçalves de Souza e. "Pela Puericultura". (Tese de doutoramento, Faculdade de Medicina e Cirurgia de São Paulo). São Paulo: Casa Vanorden, 1921, p. 14. O médico também propunha a difusão de ensinamentos de puericultura em todas as escolas primárias e secundárias do Brasil. 
de doutoramento Da protecção ao lactante em nosso meio operário, Jayme Cardoso Americano escreveu sobre a importância da criação de creches com salas de amamentação nas fábricas e sugeriu que "[...] durante as horas de amamentação nas salas para isso reservadas, as mães seriam instruídas com conselhos higiênicos relativos ao seu estado e referentes também à puericultura". ${ }^{48}$

A instrução da mãe operária era fundamental porque dela dependia a realização cotidiana de ações para o bom desenvolvimento da criança e para a educação infantil. Americano escreveu que:

[A criança] por uma educação bem dirigida virá a constituir o cidadão útil a si e à sociedade, e pela docilidade com que seu organismo obedece às imposições do meio é perfeitamente possível a governos inteligentes e bem intencionados preparar gerações de homens que, vivendo felizes conduzem sua pátria aos destinos que ela merece..$^{49}$

A possibilidade dessa educação "bem dirigida", que deveria ser implementada pelos governantes e concorreria para o progresso do país, era em grande parte responsabilidade materna, pois tinha como pré-requisito uma criança bem gestada, devidamente amamentada, criada com cuidados higiênicos e relativos à saúde. Uma educação, baseada no saber médico-científico e efetuada com a parceria da mãe (educadora primeira), que formaria o "cidadão útil a si e à sociedade". Educação que também inibiria o crescimento do número de doentes e dos denominados degenerados.

A noção de degenerescência nascida no contexto da medicina alienista no século XIX, formulada por Bénédict-Augustin Morel (1809-1873), tinha como tipo próprio o cretino, retardado ou idiota, entretanto, como "postulado de base", degenerado tornou-se uma "categoria psiquiátrica genérica" e sua combinação com teorias evolucionistas e da hereditariedade resultou em noções de degeneração da e na espécie, concorrendo para formulações de ideias sobre o tipo humano ideal e da existência de taras resultantes de "certas circunstâncias de vida" (p. ex. alcoolismo) que seriam transmitidas à descendência. ${ }^{\circ 0}$ Essas ideias, que circulavam entre os médicos e eram discutidas nas teses da Faculdade de Medicina e Cirurgia de São Paulo, também fundamentaram discursos de militantes operários que entendiam o conhecimento científico como essencial para uma educação efetiva e, portanto, transformadora.

Nos primeiros anos do século XX, artigos de jornais anarquistas de São Paulo anunciavam um futuro sombrio para os trabalhadores caso não fosse rompido o elo feito pela pobreza que unia a mulher e a fábrica, local associado à sua ruína física e que comprometia sua função primordial que era ser mãe. Mas como desfazer este elo? Como poderia a mulher trabalhadora realizar sua "missão sublime" que, segundo palavras escritas no jornal A Lanterna em 1909, era educar os filhos e exercer "[...] sua influência salutaríssima no lar e na regeneração da humanidade"?51 Militantes operários, partidários do ideal neomalthusiano que combinava controle de natalidade com a noção de degenerescência, indicavam uma possibilidade: a redução do número de filhos, pois com uma prole menor

48 AMERICANO. "Da protecção ao lactante em nosso meio operário", p. 16.

49 AMERICANO. "Da protecção ao lactante em nosso meio operário", p. 4.

50 STIKER, Henri-Jacques. "Nova percepção do corpo enfermo”. In: CORBIN, Alain; COURTINE, Jean-Jacques; VIGARELLO, Georges (dir.). História do corpo. Volume 2. $2^{\text {a }}$ edição. Petrópolis: Vozes, 2008, p. 366-367. Confira: CAPONI, Sandra. Loucos e degenerados. Rio de Janeiro: Ed. Fiocruz, 2012, p. 99-121.

51 A Lanterna. São Paulo, ano IV, n 1, 17 out 1909, p. 4. O texto é parte de um comentário feito sobre um folheto de autoria de Adelino de Pinho, diretor da Escola Moderna do bairro do Brás (São Paulo). 
seria possível ao trabalhador prescindir da contribuição financeira da mulher (e dos menores). Número reduzido de filhos significava que as crianças seriam bem gestadas, criadas e educadas, graças à atenção permanente da mãe. Artigo no A Terra Livre, de 1907, afirmava:

O proletariado que tiver muitos filhos condena a si e a sua companheira à miséria e escravidão certa e, não podendo alimentar nem cuidar bem de sua prole, só pode lançar ao mundo seres degenerados, estúpidos, sem força física nem moral, destinados somente à vida mais abjeta e mais vil. ${ }^{2}$

Permeados por essas ideias, textos de jornais anarquistas publicavam repetidamente dados estatísticos sobre "as avarias [que] caem sobre a descendência" de pais alcoólatras, tuberculosos ou sifilíticos. ${ }^{53}$ Em 1904 artigos de vários números do jornal $O$ Amigo do Povo apresentavam e defendiam a tese da redução do número de filhos e, entre julho e setembro, o periódico reproduziu a conferência "Maternidade Voluntária" de Sébastien Faure, anarquista e membro da Liga de Regeneração Humana (fundada na França por Paul Robin em 1896). Faure discutia a tese da limitação do número de filhos como forma de insubmissão à ordem vigente, destacando os benefícios da "maternidade voluntária", ou seja, ter filhos quando desejados e quantos fosse possível sustentar e educar. Para ele, "duas condições: bom nascimento e boa educação" transformariam a sociedade, pois “[...] não é entre os degenerados, entre os avariados, entre os fracos de corpo e de cérebro que se recruta o exército revolucionário". Nesse mesmo ano o jornal publicou comentário sobre o folheto "A Crescente Incapacidade das Mulheres para Amamentarem os Filhos" do doutor G. von Bunge, editado pela Revista Médica de S. Paulo, dirigida pelos doutores Victor Godinho e Arthur de Mendonça. Segundo comentário do periódico anarquista, o doutor G. von Bunge defendia no seu artigo "[a] simples verdade de constituir a procriação de filhos doentes e degenerados [devido alcoolismo, ascendentes tuberculosos ou com taras psicopáticas] o crime mais grave que o homem possa cometer". ${ }^{54} \mathrm{E}$ comentário publicado em outro número do jornal $O$ Amigo do Povo lembrava que, graças à ciência, era possível evitar filhos, mas não evitar o amor:

Hoje a higiene recebe da ciência os mais sacrossantos direitos para dizer ao tuberculoso, ao epilético, ao idiota, ao sifilítico: Amai, mas não procrieis. E a economia política que não passa afinal duma higiene da sociedade, deve dizer ao pobre que só a fome ou os asilados expostos pode oferecer aos filhos: Amai, mas não procrieis. ${ }^{55}$

Nessa época os folhetos Greve de Ventres (de Louis Bulffi) e Mulheres, não procrieis! e o boletim Salud y Fuerza (publicado pela seção espanhola da Liga de Regeneração Humana), eram divulgados entre os trabalhadores, como indicavam as propagandas nos jornais A Terra Livre, Folha do Povo e A Lanterna, ${ }^{56}$ uma forma

52 A Terra Livre, São Paulo, ano II, $\mathrm{n}^{\circ} 47,28$ set 1907, p.2.

53 O Solidário, Santos, ano II, $\mathrm{n}^{\circ}$ 23, 10 jun 1924, p.2, apud BERTUCCI, Liane Maria. Saúde: arma revolucionária, p. 128. Veja também p. 81-133.

54 FAURE, Sébastien. “Maternidade Voluntária”. O Amigo do Povo, São Paulo, ano III, n 58,23 jul 1904, p.2; n 59, 6 ago 1904, p.3; n 60, 20 ago 1904, p. 2; n 61, 3 set. 1904, p. 1-2; n 62, 17 set. 1904, p. 1-2. Bibliografia. $O$ Amigo do Povo, São Paulo, ano III, nº 50, 16 abr 1904, p.4.

55 “Amai, mas não procrieis!” O Amigo do Povo, São Paulo, ano III, nº 61, 3 set. 1904, p. 4.

56 Entre outros: A Terra Livre, São Paulo, ano I, n 11, 28 jun 1906, p. 2; Folha do Povo, São Paulo, ano I, n 22, 16 ago 1908; A Lanterna, São Paulo, ano XI, nº 154, 31 ago 1912, p. 3. 
de educar operários e, principalmente, suas mulheres. Em 1916, comunicação apresentada no Primeiro Congresso Americano da Criança explicitava a dimensão dessa divulgação que extrapolava fronteiras estaduais. No texto "A creança nas fábricas e nas officinas", o capitão Antonio Augusto Pinto Machado (administrador da Vila Proletária Marechal Hermes, Rio de Janeiro) denunciava a leitura desses "livretos" afirmando:

[...] fato que requer observação acurada, é o haver nos meios proletários quem se encarregue de traduzir Bulff, Paul Robin e Malthus, atores, como se sabe, da guerra à gestação, livretos que são hoje distribuídos fartamente nos centros de trabalho e lidos por todos, dando em resultado tão perversas teorias levar a mulher obreira a preocupar-se seriamente em não querer exercer a santa missão da maternidade. ${ }^{57}$

A persistência e a diversidade da campanha pela redução do número de filhos entre os operários eram evidentes. Em 1916, ano do Congresso realizado em Buenos Aires, e no ano seguinte, propagandas de Philagina, produto farmacêutico que segundo o fabricante evitava a gravidez indesejada, eram realizadas nos jornais A Lanterna e A Plebe..$^{58}$ Entretanto, ao contrário do que pessoas como Machado poderiam supor, para os militantes operários a questão da "maternidade voluntária" significava que a mulher deveria realizar de forma consciente a missão de ser mãe.

A partir de meados da década de 1910, quando a difusão da eugenia forneceu outros subsídios para os debates sobre a saúde dos filhos de trabalhadores, ${ }^{59}$ os militantes operários discutiram a ideia eugênica do bom casamento, ou seja, da união realizada entre pessoas saudáveis que gerariam filhos bem constituídos, associando-a ao ideal anarquista do "amor livre", que condenava o casamento civil e religioso, uma imposição social e financeira; ideal que defendia a autonomia da mulher para escolher o seu marido. ${ }^{60}$ Artigo de A Plebe de 1920, resvalando em tema que motivou discussões eugênicas sobre o exame pré-nupcial, afirmava:

Os eugenistas consideram de maneira especial a realização dos casamentos, fugindo de atenderem este fato pela questão dos interesses familiares para se incorporarem na legião dos trabalhadores da criação pátria, apoiando também as suas intenções no preceito de que do equilíbrio da família advém a expressão real da comunidade pela garantia de um tipo racional [de união]. A vida do casamento é, antes do que pareça, mais uma dúvida suspensa da responsabilidade de quem partilha e se o moralista pode falar com expressão a respeito da relação conjugal [...] para alguém tornar-se moralista é necessário também a cultura da ciência, de abstração, cujo ato concreto seria com certeza a prática da eugenia. [...] Somente a afeição sincera do homem para a mulher apagaria um pouco as verdades da ciência; porém o raciocínio empalidece o sentimento da subjetividade, e o homem senão a mulher - torna-se a criatura que delibera para esperar que a felicidade sua cresça. ${ }^{61}$

57 MACHADO, Antonio Augusto Pinto. "A creança nas fábricas e nas officinas". PRIMEIRO CONGRESSO AMERICANO DA CREANÇA, 1917, v. 1, p. 258.

58 A Lanterna, São Paulo, ano XV, n 284, 29 jan 1916, p. 4; A Plebe, São Paulo, ano I, n 1, 9 jun 1917, p. 4.

59 Entre os brasileiros ganhou ênfase, muitas vezes combinada com o ideário sanitarista, a chamada eugenia positiva e preventiva (atenção com a procriação sadia; combate a fatores ambientais que poderiam comprometer o desenvolvimento saudável das pessoas), mas existiram discussões e propostas baseadas na eugenia negativa, confira: WEGNER, Robert; SOUZA, Vanderlei S. de. "Eugenia "negativa", psiquiatria e catolicismo: embates em torno da esterilização eugênica no Brasil”. História, Ciências, Saúde - Manguinhos. Rio de Janeiro, v. 20, nº 1, p.263-288, jan-mar 2013.

60 Confira: A Voz da União. São Paulo, ano I, nº 9, 5 dez 1922, p. 1.

61 Um problema secular. A Plebe, São Paulo, ano IV, nº 74, 24 jul 1920, p. 2. 
Assim, até mesmo a "afeição sincera", justificativa para a realização do casamento, parecia ter que se submeter à eugenia. Nos jornais anarquistas foi efetiva a divulgação dessa e de outras "verdades da ciência" e a educação para a saúde (considerada uma necessidade eugênica pelo médico Jayme Americano) ${ }^{62}$ foi primordial entre militantes operários quando as questões eram a geração de filhos sadios e a manutenção da boa constituição das crianças trabalhadoras, futuros revolucionários. Educação cotidiana, realizada através de artigos, como o publicado no jornal A Lanterna, em 1911, que defendia a importância da higiene para a existência de uma "sociedade perfeita de homens sãos de corpo e de espírito". ${ }^{63}$ Uma educação efetuada informalmente: através de avisos, como o publicado no A Plebe em 1923, que convidava para "conferência educativa" sobre as causas da degenerescência e, também, realizada por meio de propagandas, como a do doutor Mario Gracho, publicada em 1921 no jornal A Vanguarda, que informava os leitores que o médico era "especialista em moléstia de crianças". ${ }^{64}$ Uma forma de educação dos trabalhadores que atravessou as três primeiras décadas do século $\mathrm{XX}$, traduzindo a apropriação e utilização de aspectos do saber médico-científico por militantes operários que os difundiam entre os trabalhadores de São Paulo (inclusive através de anúncios de médicos, os manipuladores privilegiados da ciência da saúde).

\section{Considerações finais}

No início dos anos 1920 doutorandos da Faculdade de Medicina e Cirurgia de São Paulo debateram, reelaboraram questões e fizeram propostas relacionadas à regulamentação do trabalho do menor e da mulher em fábricas e oficinas; problema cuja relevância cresceu desde o início do século XX acompanhando a industrialização do Estado e, principalmente, da cidade de São Paulo. Nesse contexto, a saúde da criança operária, desde o período de sua gestação, foi objeto de considerações que apontavam a importância da educação dos pais, notadamente da mãe, para geração e criação de filhos sadios que se tornariam homens hígidos, trabalhadores para o progresso do país. Mas, como exemplificaram as comunicações apresentadas pelo Comitê Nacional Brasileiro no Primeiro Congresso Americano da Criança, de 1916, os temas trabalho da criança e da mãe operária, com suas consequências para a saúde infantil, também foram alvos da atenção de outros profissionais, que conjugavam o conhecimento médico com diferentes saberes, como os do Direito. Como escreveu Almeida em 2006, foi da ampla discussão sobre trabalho e doença que resultou a Lei Federal de Acidentes do Trabalho de 1919, discussão que, concomitantemente, concorreu para impulsionar a construção da especialidade Medicina do Trabalho no Brasil. ${ }^{65}$

Entretanto, se os temas debatidos por representantes brasileiros no congresso de 1916 e abordados em teses médicas da primeira metade da década de 1920 devem ter colaborado para a formulação da lei de 1919 e para o processo da criação da Medicina do Trabalho (cada vez mais regulamentada a partir dos

62 AMERICANO. "Da protecção ao lactante em nosso meio operário", p. 5.

63 O problema social. A Lanterna. São Paulo, ano X, n 86, 13 maio 1911, p.1.

64 Conferencia educativa. A Plebe. São Paulo, ano V, n² 200, 13 jan 1923. Dr. Mario Gracho. A Vanguarda. São Paulo, ano I, nº 1, 25 fev 1921, p. 4.

65 ALMEIDA, Anna Beatriz de Sá. "Doenças e trabalho: um olhar sobre a construção da especialidade medicina do trabalho". In: NASCIMENTO, Dilene R. do; CARVALHO, Diana M. de; MARQUES, Rita de C. (org.) Uma história brasileira das doenças. Volume 2. Rio de Janeiro: Mauad X, 2006, p. 181. 
anos 1930), ${ }^{66}$ é importante considerar como parte desse processo as discussões de militantes operários e suas ações quando o tema era, por exemplo, trabalho infantil ou os malefícios das substâncias tóxicas para as operárias gestantes, entre outros relacionados à saúde da criança trabalhadora. Discussões que, muitas vezes baseadas em noções sobre degenerescência, no neomalthusianismo e em teses eugênicas, resultaram em uma educação diária dos trabalhadores pelos jornais anarquistas e que, em alguns momentos, ganharam mais visibilidade para a toda a sociedade de São Paulo, como nas conferências do Comitê Popular de Agitação Contra a Exploração dos Menores de 1917. Educação cotidiana e difusa que pode ter resultado em espanto de vários paulistanos que, como o capitão Antonio Augusto Pinto Machado, eram informados sobre mulheres operárias leitoras ou ouvintes das teses de Bulfi, Robin e Malthus.

Recebido em 06/02/2015 Aprovado em 14/06/2015

66 ALMEIDA, Anna Beatriz de Sá. "A Associação Brasileira de Medicina do Trabalho: locus do processo de constituição da especialidade medicina do trabalho no Brasil na década de 1940". Ciência \& saúde coletiva. Rio de Janeiro, v.13, n³, p.869-877, maio-jun. 2008; MOTA, André; SCHRAIBER, Lilia Blima. "Mudanças corporativas e tecnológicas da medicina paulista em 1930". História, ciências, saúde - Manguinhos. Rio de Janeiro, v. 16, nº 2, p. 345-360, abr-jun 2009. 